\title{
Diagnosis and staging of laryngopharyngeal tumours with flexible endoscopy: A prospective study
}

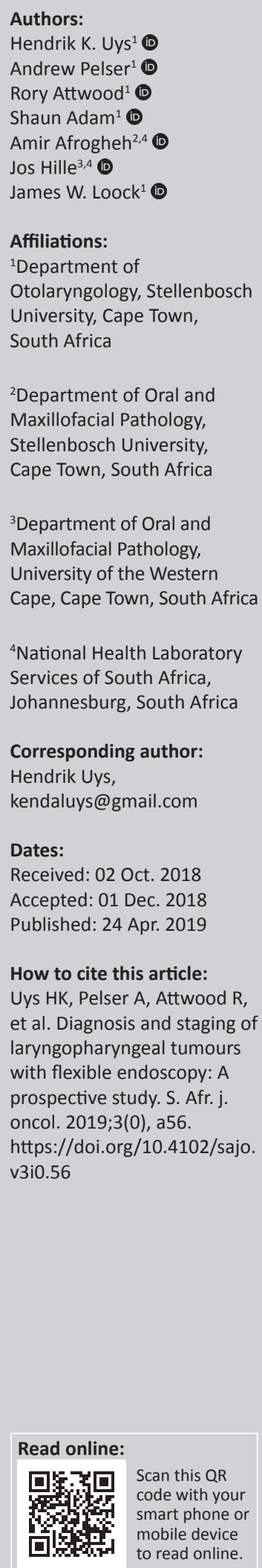

Background: Many suspected laryngopharyngeal neoplasms are examination under general anaesthesia (EUA). Office-based endoscopy is already routinely performed on all patients presenting with a suspected laryngopharyngeal neoplasm. Accurate clinical staging and tissue sampling using flexible endoscopy may eliminate the need for EUA.

Aim: To compare the use of flexible endoscopy to EUA as primary diagnostic tool of laryngopharyngeal lesions to EUA, using accuracy of tissue samples obtained and clinical staging as primary outcome measures. Duration, patient tolerance and cost implications were also assessed.

Setting: The study was performed in the outpatient department and surgical theatres of Tygerberg Hospital, Cape Town, South Africa.

Methods: A prospective study compared staging and tissue sampling accuracy with flexible endoscopy to EUA in 54 patients. Duration, tolerance and cost implications were also assessed.

Results: Flexible endoscopic biopsy had a 77.1\% sensitivity, $100 \%$ specificity and $82.2 \%$ diagnostic accuracy. Liquid-based cytology had $97.3 \%$ sensitivity, 100\% specificity and 97.9\% diagnostic accuracy in differentiating high-grade lesions from low-grade lesions. Local staging agreement occurred in $88.6 \%(n=31 / 35)$ of malignant cases. The mean duration was $15 \pm 7 \mathrm{~min} ; 86 \%$ of patients perceived the procedure as tolerable. Flexible endoscopy as a primary diagnostic tool would have avoided EUA in $68.6 \%(n=24 / 35)$ of squamous cell carcinoma cases, with a R128 232 cost savings.

Conclusion: Office-based endoscopy is an accurate, well-tolerated, time- and cost-effective primary diagnostic tool of laryngopharyngeal lesions. It reduces the number of patients requiring EUA. Further evaluation is empirical when the histopathology does not confirm the clinical suspicion of malignancy.

Keywords: office-based procedure; flexible endoscopy; biopsy; staging; larynx; pharynx.

\section{Introduction}

Diagnostic tissue sampling and accurate staging are absolute necessities for the appropriate management of all head and neck tumours. In laryngopharyngeal tumours, while squamous carcinoma is very common, the tissue sample must confirm the diagnosis, and the topographic stage and site of the lesion inform the best treatment options. The gold standard for histological and topographic assessment of laryngopharyngeal tumours is the traditional examination under general anaesthesia (EUA), which includes direct laryngoscopy, pharyngoscopy, tracheoscopy, oesophagoscopy and biopsy. This comes at a considerable cost in terms of health care expenses, theatre time and delays to definitive management.

Health care costs, combined with advances in medical science and technology, have increased the trend towards outpatient procedures wherever possible. ${ }^{1,2,3}$ Transnasal flexible endoscopy is widely performed in the outpatient setting on patients with otorhinolaryngology (ORL) problems. It allows a topographic assessment of a lesion, and tissue samples can be obtained through a working channel in the endoscope. ${ }^{4,5,6,7}$

Pressures on the public health care system are as great in South Africa as they are internationally, and this led the authors to investigate the possibility of replacing traditional EUA and biopsy for laryngopharyngeal lesions with an outpatient-based, local anaesthetic procedure.

The use of flexible endoscopy to topographically stage laryngopharyngeal tumours was first described in $1989 .{ }^{8}$ No other studies in the English literature were found that validate this technique. 
Furthermore, there are technical difficulties involved in obtaining adequate and reliable tissue samples for definitive diagnosis. The biopsy channel, and therefore the cup forceps, is very small. ${ }^{9}$

Additionally, tissue sampling and topographic staging of laryngopharyngeal lesions using flexible endoscopy need to be well-tolerated and time-efficient. We conducted a prospective study to evaluate the feasibility of this alternative to EUA.

\section{Materials and methods Patient selection}

A prospective, blinded study was conducted in a tertiary ORL setting at Tygerberg Hospital, Cape Town, South Africa. All patients with suspected laryngeal or hypopharyngeal lesions presenting between August 2011 and November 2012 were included in the study. Patients presenting with acute upper airway obstruction were excluded. The study was explained to, and written consent was obtained from, each patient for the flexible endoscopy and EUA. Ethical approval was obtained through Stellenbosch University.

\section{Technique}

Endoscopic evaluation under local anaesthetic with biopsy and liquid-based brush cytology was compared with the gold standard of EUA and biopsy. The office-based flexible endoscopic procedure was performed on every patient before proceeding with the EUA. The endoscopic procedure was performed in the consulting room by a consultant and an otolaryngology (ENT) registrar with a video tower. The nasal cavity was prepared with a $1 \%$ lignocaine-oxymetazoline spray and the oropharynx with $10 \mathrm{mg} / 0.1 \mathrm{~mL}$ lignocaine in alcohol spray. The consultant then performed the procedure using a flexible endoscope with a working channel (PENTAX FNL-15RP3). The laryngopharyngeal lesion was visualised and $1 \%$ lignocaine was sprayed onto the laryngopharyngeal lesion through the working channel of the flexible endoscope. The lesion was topographically assessed before tissue samples were taken. Cell and tissue samples were obtained through the working channel of the flexible endoscope. A transepithelial cytology sample was acquired first using the flexible brush (OLYMPUS BC-202D-3010), followed by a flexible cup forceps biopsy to obtain a histological sample. The consultant recorded his findings on a Head and Neck Staging Diagram Sheet (Appendix 1) and clinically staged the lesion using the American Joint Committee on Cancer (AJCC) 7th edition TNM classification. This stages a tumour based on the tumour's local extensiveness (T), nodal disease status $(\mathrm{N})$ and distant metastasis $(\mathrm{M})$. The duration of the procedure was recorded. Patients were asked whether they found the procedure tolerable.

Another consultant, blinded to the flexible endoscopy findings, performed the standard EUA and biopsy within
5 days of the flexible endoscopy, where the lesion was again topographically assessed and histological samples were obtained. Here too topographic assessment and TNM stage were recorded on the Head and Neck Staging Diagram Sheet.

Prior to the study, a small blinded study was performed where the two consultants involved compared their evaluation of EUA procedures, to limit inter-observer error. Each consultant assessed 10 laryngopharyngeal lesions and recorded their findings on the Head and Neck Staging Diagram Sheet. Their T-staging of the primary lesion was identical in all 10 cases.

The cells were collected using liquid-based cytology, a modern technique that improves the quality of the samples presented for assessment. ${ }^{10,11}$ The cytology preparations were assessed using the recently proposed modified liquid-based oral cytological grading and scoring system. ${ }^{10}$ The histology specimens were graded using the laryngeal intraepithelial neoplasia (LIN) system.

\section{Outcome measures}

The outcome measures were:

- accuracy of tissue samples (cytology and biopsy) obtained with the flexible endoscopy compared with the standard EUA tissue biopsy

- accuracy of clinical staging using flexible endoscopy compared with the standard EUA

- duration of the flexible endoscopic procedure

- tolerability of the flexible endoscopic procedure

- cost analysis.

\section{Statistical analysis}

Data captured were analysed by the biostatistics department at Stellenbosch University. The sensitivity, specificity and accuracy of both flexible brush cytology and flexible cup forceps biopsy were compared to the EUA biopsy result. The agreement between clinical staging using flexible endoscopy and EUA was determined. The mean duration of the procedures was calculated. Patient tolerance was assessed both subjectively, by evaluating the patient's opinion about the procedure, and objectively, by the ability to obtain an adequate tissue sample.

\section{Ethical considerations}

Ethics approval was obtained through Stellenbosch University (Reference number: N09/06/179). The authors assert that all procedures contributing to this work comply with the ethical standards of the South African Medical Research Council as well as the Guidelines for Ethical Research as set out by the Department of Health: Principles, Structures and Processes in 2004 and with the Helsinki Declaration of 1975, as revised in 2008. 


\section{Results and analysis}

Fifty-four patients were included in the study. Four patients were excluded from analysis; one patient refused flexible endoscopy, the second did not have an EUA because of anaesthetic risks, the third died before the scheduled EUA and no lesion was identified at EUA with the fourth patient, suggesting complete removal of the small, pedunculated, benign lesion with the flexible endoscopic cup forceps biopsy. Fifty patients were therefore included in the statistical analysis.

\section{Tissue sampling}

Fifty patients had tissue samples obtained with both flexible endoscopy and EUA; 30\% $(n=15)$ were benign non-neoplastic lesions and $70 \%(n=35)$ were invasive squamous cell carcinoma (SCC). The benign lesions included two vocal cord polyps, one vocal cord nodule, seven cases of dysplasia and five of inflammatory changes.

\section{Flexible endoscopic cup forceps biopsy}

Flexible endoscopic cup forceps biopsy yielded an accurate sample in 38/50 patients when compared with EUA (Table 1). The sensitivity was $77.1 \%$, the specificity was $100 \%$ and the diagnostic accuracy was $82.2 \%$. Eight false-negative results $(16 \%)$ and four inadequate biopsy samples (8\%) were obtained. Of the invasive SCC diagnosed on EUA biopsy, flexible endoscopic biopsy identified 68.6\% $(n=24 / 35)$.

\section{Flexible endoscopy-guided liquid-based cytology}

Flexible endoscopy-guided liquid-based cytology was accurate in $48 / 50$ patients in differentiating high-grade lesions from low-grade lesions. The sensitivity was 97.3\%, the specificity was $100 \%$ and the diagnostic accuracy was $97.9 \%$. One false-negative result and one inadequate smear were obtained.

TABLE 1: Flexible endoscopic biopsy versus examination under general anaesthesia biopsy.

\begin{tabular}{|c|c|c|c|c|c|c|}
\hline \multirow{2}{*}{$\begin{array}{l}\text { Variable } \\
\text { EUA biopsy }\end{array}$} & \multicolumn{6}{|c|}{ Flexible endoscopic biopsy } \\
\hline & No dysplasia & LIN I & LIN II & LIN III & Invasive SCC & No tissue \\
\hline No dysplasia & 10 & - & - & - & - & 2 \\
\hline LIN I & - & - & - & - & - & - \\
\hline LIN II & - & - & 1 & - & - & - \\
\hline LIN III & $2^{\mathrm{a}}$ & - & - & 3 & - & 1 \\
\hline Invasive SCC & $6^{\mathrm{a}}$ & - & - & - & 24 & 1 \\
\hline
\end{tabular}

Note: $n=50$; bold text $=$ agreement.

EUA, examination under general anaesthesia; LIN, laryngeal intraepithelial neoplasia; LIN I, mild dysplasia; LIN II, moderate dysplasia; LIN III, severe dysplasia or carcinoma in situ; SCC, squamous cell carcinoma.

a, false negatives.

TABLE 2: Staging of laryngopharyngeal tumours with flexible endoscopy against examination under general anaesthesia

\begin{tabular}{lccccc}
\cline { 1 - 3 } Variable & \multicolumn{5}{c}{ EUA } \\
\cline { 1 - 3 } \cline { 4 - 6 } Flexible endoscopy & & T1 & T2 & T3 & T4a \\
\hline T1 & $\mathbf{8}$ & 1 & 1 & - \\
T3 & - & $\mathbf{4}$ & 1 & 1 \\
T4 & - & - & $\mathbf{1 6}$ & - \\
\hline
\end{tabular}

Note: $n=35$; bold text $=$ agreement.

EUA, examination under general anaesthesia. T1 to T4 indicates local disease extent.

\section{Clinical staging}

T-stage agreement occurred in $88.6 \%(n=31 / 35)$. There was an even distribution of primary sites, with $37.1 \%(n=13)$ supraglottic, $34.3 \%(n=12)$ glottic and $28.6 \%(n=10)$ hypopharyngeal lesions. Table 2 plots staging using flexible endoscopy against EUA. The shaded area indicates agreement. The numbers above the shaded area are when flexible endoscopy underestimated the T-stage. The T4a lesions identified on flexible endoscopy were two supraglottic lesions with tongue base involvement and a hypopharyngeal lesion with soft tissue invasion through the thyroid cartilage.

\section{Tolerability}

Subjectively, $86 \%(n=43 / 50)$ of patients perceived the procedure as tolerable. Five of the poorly tolerated cases had glottic lesions and three occurred during the first month of the study. Objectively, when considering tolerability as the ability to obtain a tissue sample, $92 \%(n=46 / 50)$ of patients tolerated the procedure.

\section{Duration}

The mean duration of the flexible endoscopic procedure with staging and cell and tissue sampling was $15 \pm 7 \mathrm{~min}$. The time taken per procedure improved during the study period, with the majority $(n=5 / 9)$ of the longer procedures (more than $20 \mathrm{~min}$ ) occurring during the first month of the study (Figure 1); 83\% $(n=44 / 53)$ of the procedures took less than $20 \mathrm{~min}$. The longer procedures were predominantly glottic lesions $(n=6 / 9)$.

\section{Cost analysis}

An EUA at our institution, including an overnight stay, is R5343 per case. A histological diagnosis of SCC was confirmed in 24 cases by a flexible endoscopic biopsy. Twenty-four EUA procedures could therefore have been avoided if flexible endoscopy was used as a primary diagnostic tool. This equates to a total saving of R128 232. Further costs, such as transport fees, were not included in the calculations.

\section{Discussion}

Health care is moving increasingly towards office-based procedures. This avoids unnecessary admissions, reduces theatre time and is preferred by patients. ${ }^{1}$ Office-based flexible endoscopic procedures are safe and well tolerated. ${ }^{5,7}$ Our study investigated the accuracy of different tissue sampling techniques and the clinical staging with flexible endoscopy.

\section{Tissue sampling}

\section{Flexible endoscopic cup forceps biopsy}

Cup forceps biopsy with flexible endoscopy was compared to biopsy under EUA. Our results showed a 77.1\% sensitivity, $100 \%$ specificity, $82.2 \%$ accuracy and $8 \%(n=4 / 50)$ inadequate samples. Other recent studies have shown similar sensitivities 


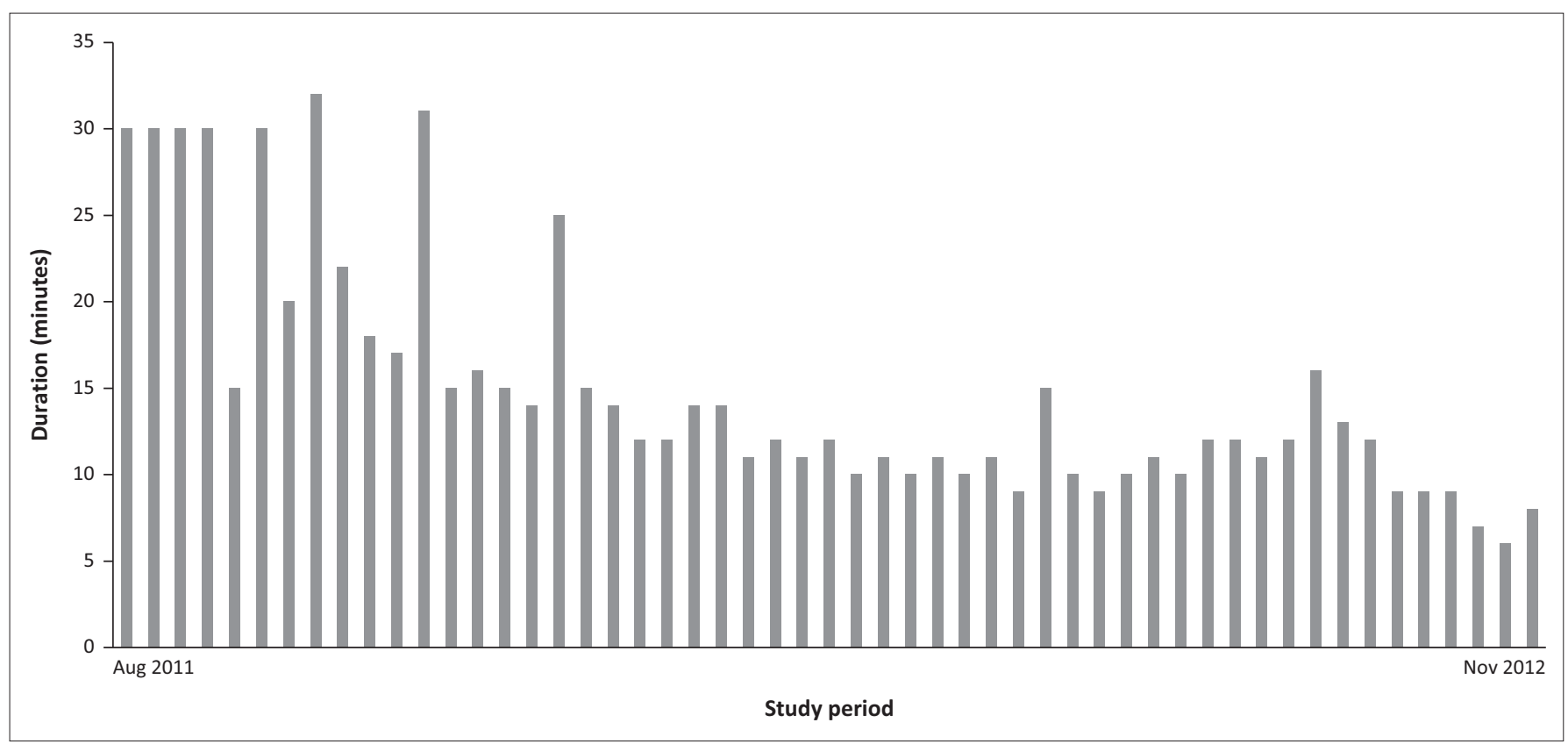

FIGURE 1: Duration of flexible endoscopic procedures.

of $60 \%-81 \%$ with flexible endoscopic cup forceps biopsy in diagnosing laryngeal tumours. ${ }^{4,6,12}$ The variability in the sensitivity and the false-negative rates in these studies may contribute to the different proposed recommendations. Richard et al. advocate EUA for all suspected malignancies, while others recommend EUA only when the clinical suspicion of a malignancy is not confirmed with the flexible endoscopic cup forceps biopsy., ${ }^{4,68}$ The former, however, found flexible endoscopy to be an inadequate diagnostic tool because of the correct identification of squamous carcinoma in only $15 \%$ of cases. This contrasts with our study results, where flexible endoscopic cup forceps biopsy correctly identified $68 \%(n=24 / 35)$ of SCC.

Additionally, we did not generate any false-positive results. Our $16 \%$ false-negative rate compares well to the recent study by Farías et al. and emphasises the importance of clinical correlation with histological assessment. ${ }^{12}$ These results confirm that the majority, but not all, of suspected malignant laryngopharyngeal lesions can be identified using flexible endoscopic cup forceps biopsy. It highlights the importance of clinical correlation with the histological sample and that clinically suspicious lesions with histologically benign results should be interpreted with caution.

\section{Transepithelial flexible brush liquid-based cytology}

Conventional exfoliative cytology has been used as an alternative to biopsy in laryngeal lesions. It was found to have a poor quality and high number of inadequate specimens, with sensitivities of $70.3 \%-93.3 \%$ and inadequate samples of $3.3 \%-5.0 \%$ reported. ${ }^{13}$ In this study, we obtained transepithelial flexible brush cytological samples and analysed them using advanced liquid-based cytology. Our sensitivity of $97.3 \%$ using liquid-based cytology is a marked improvement on the $70.3 \%$ sensitivity reported by Farías et al. with conventional exfoliative laryngeal brush cytology. ${ }^{12}$
The cytological grading system used allows differentiation between high-grade and low-grade lesions. It cannot show invasion through the basement membrane and therefore cannot confirm an invasive carcinoma. ${ }^{10} \mathrm{~A}$ histological tissue sample would still be necessary to differentiate high-grade dysplasia from malignancy. It may prove very useful in cases where dysplasia is suspected when a suspected benign lesion has not responded to conservative management.

We recommend flexible endoscopic cup forceps biopsy as the initial tissue sampling technique in every case where malignancy is clinically suspected. A clinically benign lesion may be assessed using a transepithelial flexible brush with liquid-based cytology if any concern regarding possible dysplasia exists. This allows exclusion of high-risk lesions with minimal mucosal trauma. Benign low-grade lesions do not need further tissue biopsies, whereas cytological highgrade lesions need a tissue biopsy to exclude malignancy (see Figures 2 and 3).

\section{Clinical staging}

We used flexible endoscopy as an alternative to EUA. Flexible endoscopy has several theoretical advantages over EUA. These include assessment of vocal cord mobility, a bird's-eye view of the laryngopharynx, better muscle tone in an awake patient, manoeuvres to expose the pyriform fossae and a lower risk of mucosal injury. Our study found T-stage agreement in $88.6 \%(n=31 / 35)$ of patients between these two techniques. This is comparable to the initial study by Bastian et al., where indirect laryngoscopy was equivocal or better than EUA in $82.1 \%(n=32 / 39)$ of patients. ${ }^{8}$

Flexible endoscopy underestimated the extent of the lesion in four of our cases. They were two supraglottic lesions where base of tongue and pre-epiglottic space involvement were not identified on flexible endoscopy and a glottic lesion 


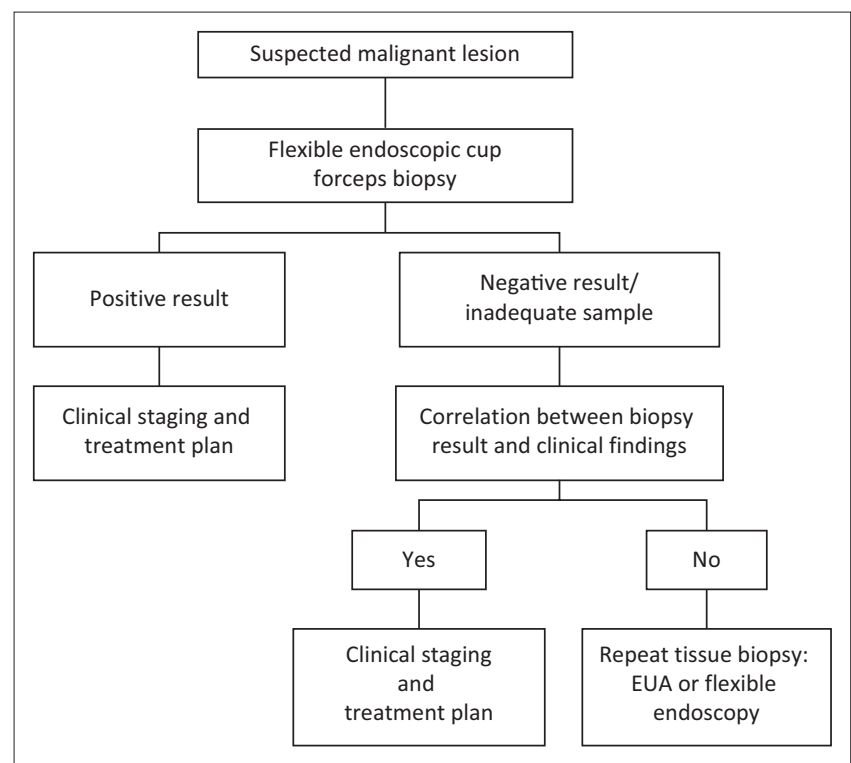

FIGURE 2: Algorithm for tissue sampling of suspected malignant laryngopharyngeal lesions.

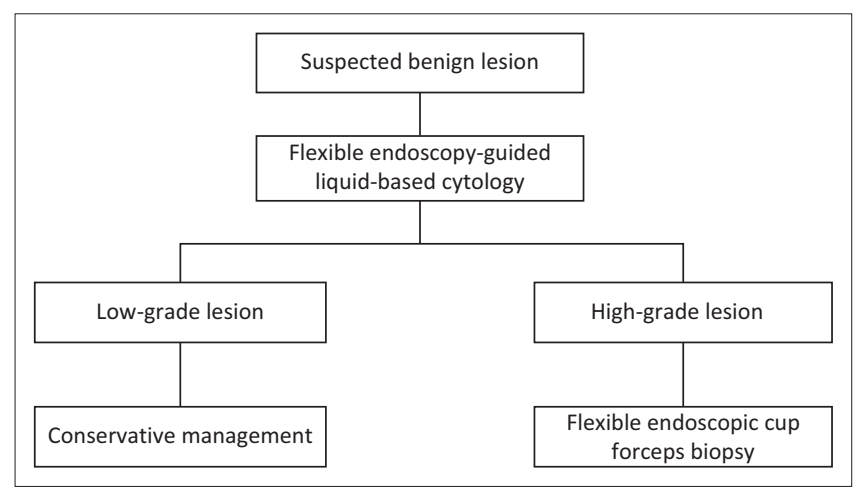

FIGURE 3: Algorithm for tissue sampling of suspected benign laryngopharyngea lesions where dysplasia has to be excluded.

where the subglottic extent was not identified. The fourth case was a glottic lesion where mobile vocal cords were incorrectly assessed as fixed on EUA, so flexible endoscopy was in fact more accurate. Looking at the cases of understaging with flexible endoscopy, the base of tongue involvement in the abovementioned supraglottic lesion was initially not identified but only suspected on EUA and needed confirmation with radiological imaging. Similarly, the other two cases with pre-epiglottic space and subglottic involvement could have been identified on imaging. The authors acknowledge that radiological imaging improves the clinical assessment of head and neck tumours. Zbären et al. found that the combination of clinical evaluation and imaging significantly improves staging accuracy compared to clinical evaluation alone. ${ }^{14}$ Imaging is routinely performed on all patients with laryngopharyngeal tumours in most developed countries, but is used more selectively in the developing world. The primary focus of the study, however, was to compare the clinical assessment accuracy using flexible endoscopy to EUA. Computed tomography imaging was performed and the radiological findings were included in the final clinical staging of every case. The radiological findings were simply excluded from the initial clinical assessment to allow a better comparison between flexible endoscopy and EUA.

Bastian et al. found staging of the hypopharynx using flexible endoscopy inferior to EUA. ${ }^{8}$ Our study showed no disagreement in the topographic staging of hypopharyngeal lesions, but the small number of cases per subsite makes further analysis unreliable. Larger study sample sizes are necessary to draw firm conclusions about the accuracy of topographic staging in specific subsites.

The authors believe that the combination of flexible endoscopy with radiological imaging obviates the need for EUA to topographically stage laryngopharyngeal lesions in most cases. The few cases where a bulky tumour limits the assessment of all subsites with flexible endoscopy should be staged by EUA.

\section{Patient tolerability}

This study found that the flexible endoscopic procedure was well tolerated. Subjectively, $86 \%(n=43 / 50)$ of patients perceived the procedure as tolerable, while objectively, $92 \%$ ( $n=46 / 50)$ of patients tolerated the procedure well enough to permit tissue sampling. Many authors assess tolerability subjectively, while some consider completion of a procedure as patient tolerability. ${ }^{5}$ Our results show good correlation between the subjective assessment of tolerability and the ability to obtain tissue samples. A scale to measure the degree of tolerability was not used; patients simply stated whether they found a procedure tolerable or not.

Glottic lesions and the clinician's experience with the procedure were identified as factors contributing to patient tolerability, which directly affected the duration of the procedure. Patient tolerability may be improved by ensuring adequate glottic anaesthesia. A recent study identified the laryngeal drip, which is a topical local anaesthetic dropped through the working channel of the flexible endoscope, as a significant contributor to patient discomfort. ${ }^{15}$ In that study, patient tolerance and completion rates improved significantly when using nebulised lignocaine for transnasal tracheoscopy. Another prospective multicentre study evaluated patient tolerance of in-office laryngeal procedures and noted no difference in patient discomfort when comparing two different techniques for laryngeal topical anaesthesia. ${ }^{7}$ Nebulised lignocaine formed part of both techniques. The addition of nebulised lignocaine may further improve patient tolerability and allow better assessment of the subglottis.

\section{Duration}

The improvement in the length of time of the flexible endoscopic procedure during the study shows the role clinical experience with the technique plays. An initial learning curve is to be expected when mastering any new skill. The short duration of less than $20 \mathrm{~min}$ in the majority (83\%) of cases should not disrupt the outpatient environment and makes this a viable outpatient procedure. 


\section{Conclusion}

Flexible endoscopy in the outpatient setting to stage and biopsy laryngopharyngeal lesions is a cost-effective, timeefficient, well-tolerated procedure. Topographic staging is accurate and tissue biopsies are representative in the majority of cases. Examination under anaesthesia should only be considered in cases where the tissue biopsy obtained on flexible endoscopy does not confirm a suspected malignant lesion. Patient tolerance and the duration of the procedure improve with the endoscopist's experience.

The authors recommend the use of flexible endoscopy in the outpatient setting as the initial primary diagnostic tool in all cases with a suspected laryngopharyngeal lesion without acute upper airway obstruction.

\section{Acknowledgements Competing interests}

The authors declare that they have no financial or personal relationships that may have inappropriately influenced them in writing this article.

\section{Authors' contributions}

The protocol was prepared by A.P., A.A., J.H. and J.W.L. Ethical approval was obtained by A.A. Data collection was performed by A.P., R.A., A.A., J.H. and S.A. H.K.U. and J.W.L. analysed the data and wrote the article.

\section{Disclaimer}

The views expressed in the submitted article are the views of the authors and do not reflect an official position of the institution concerned.

\section{References}

1. Rosen CA, Amin MR, Sulica L, et al. Advances in office-based diagnosis and treatment in laryngology. Laryngoscope. 2009;119(11):185-212. https://doi.org/ 10.1002/lary.20712

2. Simpson CB, Amin MR. Office-based procedures for the voice. ENT J. 2004:83 (suppl 2):6-9.

3. Woo P. Office-based laryngeal procedures. Otolaryngol Clin North Am. 2006;39:111-133. https://doi.org/10.1016/j.otc.2005.11.008

4. Richards AL, Sugumaran M, Aviv JE, Woo P, Altman KW. The utility of officebased biopsy for laryngopharyngeal lesions: Comparison with surgical evaluation. Laryngoscope. 2015;125(4):909-912. https://doi.org/10.1002/lary. 25005

5. Lippert D, Hoffman MR, Dang P, McCulloch TM, Hartig GK, Dailey SH. In-office biopsy of upper airway lesions: Safety, tolerance, and effect on time to treatment. Laryngoscope. 2015;125(4):919-923. https://doi.org/10.1002/lary.25007

6. Cohen JT, Safadi A, Fliss DM, Gil Z, Horowitz G. Reliability of a transnasal flexible fiberoptic in-office laryngeal biopsy. JAMA Otolaryngol Head Neck Surg. 2013;139(4):341-345. https://doi.org/10.1001/jamaoto.2013.38

7. Young VN, Smith LJ, Sulica L, Krishna P, Rosen CA. Patient tolerance of awake, inoffice laryngeal procedures: A multi-institutional perspective. Laryngoscope. 2012;122(2):315-321. https://doi.org/10.1002/lary.22185

8. Bastian RW, Delsupehe KG. Indirect larynx and pharynx surgery: A replacement for direct laryngoscopy. Laryngoscope. 1996;106(10):1280-1286. https://doi.org/ 10.1097/00005537-199610000-00022

9. Afrogheh A, Pelser A, Hille J, Attwood R, Loock J, Schubert PT. Application of liquidbased transepithelial flexible brush cytology in the detection of high-grade laryngeal mucosal lesions. Diagn Cytopathol. 2015;43(1):21-27. https://doi.org/ $10.1002 / d c .23180$

10. Afrogheh A, Wright CA, Sellars SL, et al. An evaluation of the Shandon Papspin liquid-based oral test using a novel cytologic scoring system. Oral Surg Oral Med Oral Pathol Oral Radiol. 2012;113(6):799-807. https://doi.org/10.1016/j.00oo. 2012.01.027

11. Hoda RS. Non-gynecological cytology on liquid-based preparations: A morphological review of facts. Diagn Cytopathol. 2007;35(10):621-634. https://doi.org/10.1002/ dc. 20698

12. Farias FC, Cobeta I, Souviron R, et al. In-office cup biopsy and laryngeal cytology versus operating room biopsy for the diagnosis of pharyngolaryngeal tumors: Efficacy and cost-effectiveness. Head Neck. 2015;37(10):1483-1487. https://doi. org/10.1002/hed.23781

13. Thomsen J, Olsen J, Thomsen KA. Exfoliative cytology in the diagnosis of laryngeal malignancy. J Laryngol Otol. 1975;89:281-287. https://doi.org/10.1017/S00222 15100080385

14. Zbären $P$, Becker $M$, Läng $H$. Staging of laryngeal cancer: Endoscopy, computed tomography and magnetic resonance versus histopathology. Eur Arch Oto-RhinoLaryngol. 1997;254(suppl 1):S117-S122. https://doi.org/10.1007/BF02439740

15. Sharma GK, Verma SP. Is nebulized lidocaine adequate topical anesthesia for diagnostic transnasal tracheoscopy? Ann Otol Rhinol Laryngol. 2015;124: 545-549. https://doi.org/10.1177/0003489415570929 


\section{Appendix 1 - Head and Neck Staging Diagram Sheet}
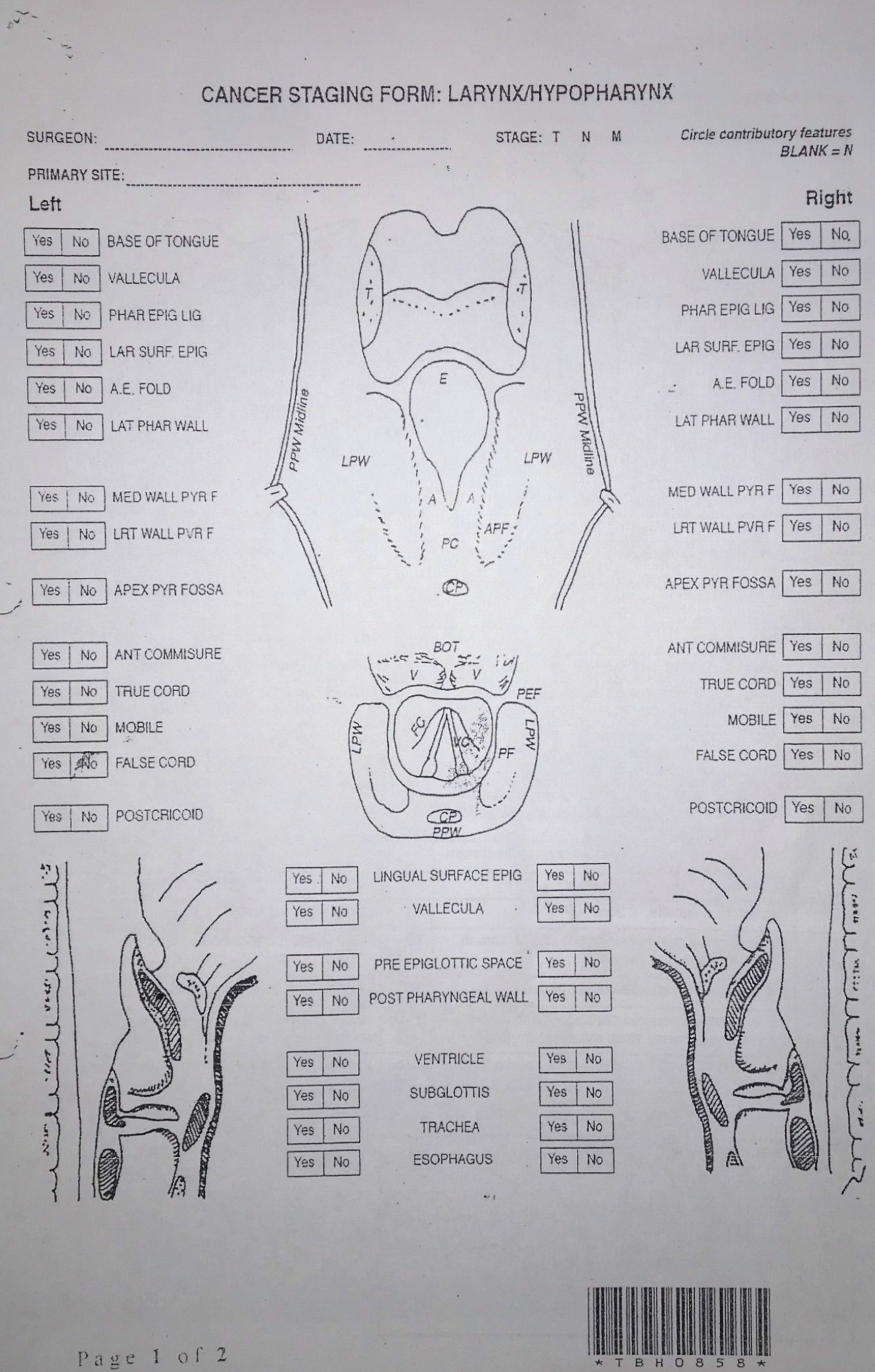

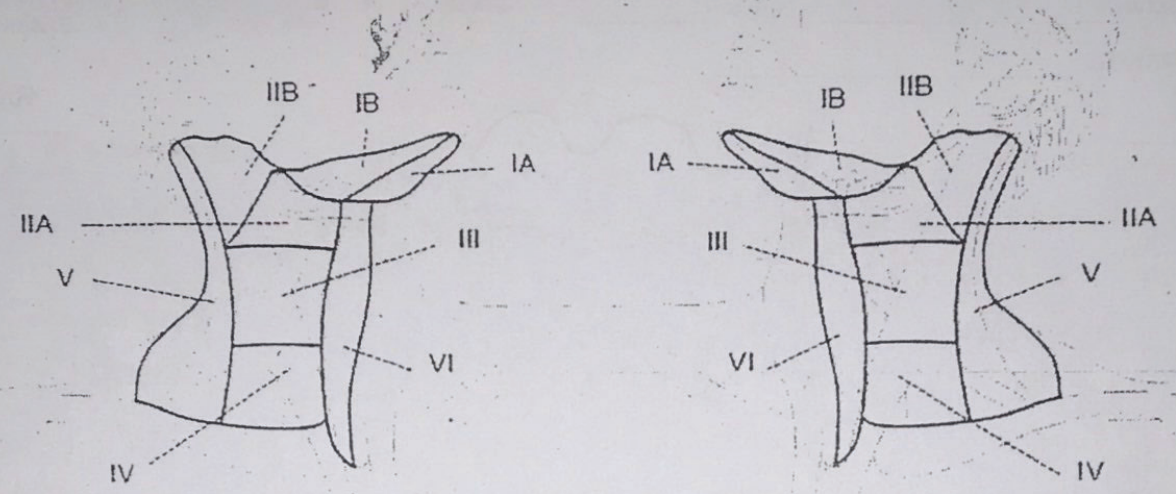

\begin{tabular}{|c|c|c|c|}
\hline & SUPRAGLOTTIS & & GLOTTIS \\
\hline Tx & Primary tumour cannot be assessed & Tia & $\begin{array}{l}1 \text { cord andvor antpost commissure involved, } \\
\text { mobile }\end{array}$ \\
\hline TO & No primary tumour & T1b & $\begin{array}{l}2 \text { cords and/or antpost commissure involved. } \\
\text { motile }\end{array}$ \\
\hline Tis & Carcinoma in situ & T2 & Involves supra/subglottis. \pm impaired cord mobility \\
\hline T1 & Limited to 1 subsite of supraghottis. mobile cords & T3 & Limited to endolarymx, cord fixed \\
\hline T2 & $\begin{array}{l}\text { >1 subsite involved (mucosa of BOT, vallecular, } \\
\text { median wall of pirform tossa), iarynx not fixed }\end{array}$ & $\mathrm{T} 4 \mathrm{a}$ & $\begin{array}{l}\text { Thyroid cartilage invasion, and/or soft tissue neck, } \\
\text { oropharynx, thyroid gland, oesophagus, trachea }\end{array}$ \\
\hline T3 & $\begin{array}{l}\text { Limited to larynix, cord fixed and/or invades } \\
\text { paraglottic, pre-epiglottic spaces and/or lateral } \\
\text { wall of piritorm tossa }\end{array}$ & T4b & Prevertabral space, carotid artery, mediastinum \\
\hline T4a & $\begin{array}{l}\text { Thyroid cartilage invasion, extra-faryngeal } \\
\text { spread (oropharynx. oesophagus, thyroid. neck } \\
\text { soft tissue) }\end{array}$ & & \\
\hline T4b & Prevertebral space, carotid artery, mediastinum & & \\
\hline & HYPOPHARYNX & & SUBGLOTTIS \\
\hline $\mathrm{T} 1$ & Limited to 1 subsite. $<2 \mathrm{~cm}$ & T1 & Limited to subglottis \\
\hline T2 & $\begin{array}{l}\text { Invades }>1 \text { subsite or adjacent site, } 2-4 \mathrm{~cm} \text { in } \\
\text { size, hemilarynx not fixed }\end{array}$ & $\mathrm{T} 2$ & Onto cords \pm impaired mobility \\
\hline T3 & $>4 \mathrm{~cm}$ in size, \pm invades oesophagus & T3 & Limited to larynx, cord fixed \\
\hline T4a & $\begin{array}{l}\text { Involves thyroid/cricoid cartilage, central soft } \\
\text { tissues (nyoid bone, strap muscles, thyroid }\end{array}$ & $\mathrm{T} 4 \mathrm{a}$ & $\begin{array}{l}\text { Involves thyroidicricoid cartilage, } \pm \text { oesophagus, } \\
\text { trachea, oropharynx, strap muscles }\end{array}$ \\
\hline T4b & Prevertabral space, carotic artery, mediastinum & $T 4 \mathrm{~b}$ & Prevertabtal space, carotid artery, mediastinum \\
\hline
\end{tabular}

Neck nodes

\begin{tabular}{|l|l|}
\hline Nx & Neck nodes cannot be assessed \\
\hline N0 & No neck nodes evident \\
\hline N1 & Single ipsilateral node, $<3 \mathrm{~cm}$ \\
\hline N2a & Multiple ipsilateral nodes, $3-6 \mathrm{~cm}$ \\
\hline N2b & Multiple ipsitateral nodes $<6 \mathrm{~cm}$ \\
\hline N2c & Bitateraltcontralateral nodes $<6 \mathrm{~cm}$ \\
\hline N3 & Node $>6 \mathrm{~cm}$ \\
\hline
\end{tabular}

